\title{
A study on ER stress-induced apoptosis pathway in cervical cancer HeLa cells treated with biosynthesized gold nanoparticles
}

\author{
M. R. Kamala Priya* and Priya R. lyer
}

\begin{abstract}
Background: The expression of apoptotic family of protein plays a major role in induction of programmed cell death. There are six major apoptotic proteins such as Caspase 12, Bcl 2, BAX, Cytochrome c, PARP3 and Mcl1. All these proteins have crucial role in the regulation of apoptosis through mitochondrial degradation, DNA damage, nuclear condensation and eventually cell death of the cancerous cells. It was observed that the apoptotic pathway has been initiated in the cancer cells from the expression of the apoptotic proteins. The results emphasized that the apoptotic cell death has been induced by the nanomaterials against cervical cancer HeLa cell line.
\end{abstract}

Methods: Initially, the nanomaterials were individually checked for potential anticancer activities through MTT assay. The cervical cancer HeLa cell line was treated with nanoparticles, nanoconjugates, nano-dox conjugate and chitosannano-dox conjugates. The cell lysates were processed for SDS-PAGE followed by Western blotting. The apoptotic expression has been studied for six major apoptotic proteins such as Caspase 12, Bcl 2, BAX, Cytochrome C, PARP3 and Mcl 1.

Results: In the present study, the biosynthesized gold nanoparticles, nanoconjugates, nano-dox conjugate, chitosan-nano-dox conjugate were treated against cervical cancer HeLa cell line. The results demonstrated anticancer effects of the nanocompounds implying nanoparticles induced apoptotic pathway in the cancer cells. Further apoptotic expression was studied for six major apoptotic proteins such as Caspase 12, Bcl 2, BAX, Cytochrome C, PARP3 and Mcl 1. The present study was focussed on anticancer efficiency of biosynthesized nanomaterials.

Conclusions: The in vitro anticancer study showed that the nanomaterials induced cell death over the treated cervical cancer cells. In the process of apoptotic cell death, the caspase cascade pathway was activated. The gene expression was checked in line with some of the genes involved in apoptosis, cell death. The expression was checked for Caspase 12, BAX, BCl2, cyt c, PARP3 and Mcl 1. The expression of apoptotic proteins suggested that the cancer cell death was mediated through ER stress-induced pathway involving the major apoptotic proteins.

Keywords: Apoptosis, Cervical cancer, HeLa cells, Gold nanoparticles, Doxorubicin

\section{Background}

Induction of apoptosis in cancerous cell by engineered nanoparticles provides a novel feasible opportunity for cancer therapy. Nanomaterials have been proven in

*Correspondence: brajuraj@yahoo.com

Post Graduate and Research Department of Biotechnology, Women's

Christian College, College Road, Chennai, Tamil Nadu 600006, India numerous studies to induce cancer cell apoptosis. Cell membranes consist of different receptors that function in cell-cell signalling, cell adhesion, interaction and immune recognition of foreign substances. Nanomaterials communicate on the cell membrane and attach to surface receptors and bring about the cytotoxic responses. The nanoparticles produce excessive reactive oxygen species (ROS) which result in the peroxidation of lipids, 
protein, cellular organelles and genetic material. The reactions lead to the induction of apoptotic pathway in the cells either through intrinsic pathway or extrinsic pathway by p53 activation. The activated p53 causes increased levels of BAX, cyt c, Caspase 9, Caspase 3, Caspase 12 leading to apoptosis (Ma and Yang 2016).

Bcl-2 family of proteins play the central role in regulation of apoptosis. The regulatory proteins include anti-apoptotic proteins $\mathrm{Bcl}-2, \mathrm{Bcl}-\mathrm{XL}, \mathrm{Bcl}-\mathrm{W}, \mathrm{Mcl}-1$, proapoptotic proteins $\mathrm{BAX}, \mathrm{Bcl}-\mathrm{XS}$ and apoptosis-inducing BH3-domain death proteins (Adhya et al. 2006). Bcl2 L1 family of proteins has two distinctive functional isoforms, $\mathrm{Bcl}-\mathrm{xL}$ acting as apoptotic inhibitor and Bcl-xS acting as apoptotic activator. Bcl-xS promotes apoptosis by caspase and BH3-dependent cascade leading to release of Cytochrome c. Bak and BAX proteins play an important role in the caspase cascade (http://atlasgeneticsoncology. org/Genes/GC_BCL2L1.html).

Caspases are another family of proteinases which induce apoptotic pathway and inflammation. Caspase 12 is a protein with a prominent role in ER stress-induced apoptosis and particularly involved in apoptosis induced by viral infections (Kalai et al. 2003). PARP3 is a DNA damage repair molecule which is degraded by Caspase 3 and other cysteine proteinases in the process of apoptosis. The degradation of PARP proteins is indicated as one of the signs of apoptotic pathway (Hou et al. 2018).

\section{Methods}

\section{Preparation of nanoparticles}

The nanoparticles used in this study were biosynthesized using chloroauric acid and plant extracts as reducing and stabilizing agents. The gold nanoparticles (AuNPs) and nanoconjugates (AuNC) were biosynthesized using green extracts of medicinal plants such as Andrographis paniculata, Catharanthus roseus, Cassia auriculata, Calophyllum inophyllum, Annona muricata, Guazuma ulmifolia, Justicia gendarussa, Cinnamomum aromaticum, Aegle marmelos, Piper nigrum and Camellia sinensis as discussed previously in our other reports (Kamala Priya and Iyer 2014a). The characterization was carried out to get an insight of the morphology and size of the nanomaterials (Kamala Priya and Iyer 2015a, 2021). The optimization of the underlying parameters such as temperature and $\mathrm{pH}$ was carried out, which played crucial role in the synthesis (Kamala Priya and Iyer 2014b). The applications of gold nanoparticles (Kamala Priya and Iyer 2015b), in vitro cytotoxicity (Kamala Priya and Iyer 2019a) and anticancer assay (Kamala Priya and Iyer 2014c, 2019b, 2020a, b, c) and anti-HIV assay (Priya et al. 2021) were carried out in different cell lines. The results demonstrated non-toxicity of the nanomaterials to normal cell line.

\section{In vivo animal study of nanoparticles}

The biosynthesized gold nanoparticles were subjected to in vivo acute and chronic toxicological effects on Wistar rats as animal model system which has been stated in our other reports. All those experimental procedures have been adopted as per OECD guidelines and approved by the Institutional Animal Ethics Committee (IAEC) and Committee for the Purpose of Control and Supervision of Experiments on Animals (CPCSEA). The results of that study emphasized that the biosynthesized nanocompounds were non-toxic to the treated animal model system (Kamala Priya and Iyer 2020d).

\section{Sodium dodecyl sulphate: polyacrylamide gel electrophoresis Preparation of the cell lysates}

The cervical cancer HeLa cell line was treated with nanoparticles, nanoconjugates, nano-dox conjugate and chitosan-nano-dox conjugates. Doxorubicin was maintained as the drug control for the assay. After $24 \mathrm{~h}$ of treatment, the plates were harvested for cell lysates. The supernatant was collected separately in $2 \mathrm{ml}$ microfuge tubes. The adhered cells were scraped using cell scraper with $1 \mathrm{ml}$ of media for cell proteins and collected in $2 \mathrm{ml}$ microfuge tubes. The microfuge tubes were centrifuged at $4000 \mathrm{rpm}$ for $10 \mathrm{~min} .200 \mu \mathrm{l}$ of the supernatant was collected and stored for further assay. The cells were washed with PBS and centrifuged at $4000 \mathrm{rpm}$ for $10 \mathrm{~min}$. The pellet was resuspended with fresh PBS and centrifuged at 10,000 rpm for $10 \mathrm{~min}$. The supernatant was discarded, and $200 \mu \mathrm{l}$ of NP-40 lysis buffer was added to the pellet, mixed well and stored at $-20^{\circ} \mathrm{C}$ for further use (Eslami and Lujan 2010).

\section{Protein concentration: PEG}

The concentration of the proteins in the sample was increased using PEG (polyethylene glycol). The samples were placed in dialysis membrane and kept immersed in PEG to enable active transport of molecules across the membrane.

Procedure $200 \mu \mathrm{l}$ of the samples was placed in the dialysis bags. The dialysis bag was clipped at both the ends. The dialysis membranes were kept immersed in excess quantity of PEG in Petri dishes. Fresh PEG was added at an interval of 5-10 min, and the membrane was checked for concentration of the samples. The PEG dialysis was carried out for 15-20 min. The samples were recovered from the dialysis membranes and stored at $-20^{\circ} \mathrm{C}$ for further usage (Ludwig et al. 2018). 


\section{Protein estimation}

BSA was used as the standard for protein estimation of the samples. $20 \mu \mathrm{l}$ of PBS was added to all the wells. About 5 different concentration of the BSA standard was added along with PBS. $20 \mu \mathrm{l}$ of sample was added to the wells along with PBS. Further $200 \mu \mathrm{l}$ of Bradford's reagent was added to all the wells. The plate was incubated in dark for $10 \mathrm{~min}$. The absorbance was read at $595 \mathrm{~nm}$. The concentration of the protein was estimated from the standard curve of BSA (He 2011).

\section{Sample preparation and loading}

All the nanocompounds were initially screened for in vitro anticancer activity in cervical cancer HeLa cell line at all different concentrations of the nanoparticles (Kamala Priya and Iyer 2014c, 2019a, b, 2020a, b, c). The concentrations of the nanoparticles with efficient $\mathrm{IC}_{50}$ (inhibitory concentration 50) were further preceded for Western blot. $20 \mu \mathrm{l}$ of the sample $+5 \mu \mathrm{l}$ of $\beta$-mercaptoethanol dye were taken in $1 \mathrm{ml}$ microfuge tubes. The samples were heated at $95{ }^{\circ} \mathrm{C}$ in dry bath for $10 \mathrm{~min}$. Tris-glycine electrophoresis buffer was poured into the upper and lower chambers of the electrophoresis apparatus. $20 \mu \mathrm{l}$ of the denatured protein sample was loaded in each well. $5 \mu \mathrm{l}$ of a molecular weight standard was loaded into one lane of the gel. The tank was connected to the power supply, and the electrophoresis was started with an initial voltage of $30 \mathrm{~V}$ and maintained at this voltage until the sample has completely entered the stacking gel followed by a running voltage of $70 \mathrm{~V}$. After the tracking dye reached the bottom of the gel, the current was stopped and the gel was removed from the plates and processed for Western blotting (Gallagher 2012).

\section{Coomassie brilliant blue (CBB) staining: SDS-PAGE}

The SDS-PAGE gel was stained using Coomassie Brilliant Blue dye to visualize the separated protein bands. After the tracking dye reached the bottom of the gel, the current was stopped and the gel was removed from the plates. The gel was kept immersed in the CBB dye and left overnight at $4{ }^{\circ} \mathrm{C}$ with continuous agitation. The dye was removed, and the gel was washed in destainer. The individual protein bands were visualized which represented the various proteins present in the sample that were separated based on their molecular weight. Genedirex blultra prestained protein ladder has been used as the prestained protein marker (https://www. protocolsonline.com/protein-science/coomassie/).

\section{Western blotting}

After electrophoresis of proteins, the gel was transferred to the transfer buffer. The gel, membrane, paper stack and the filter paper were equilibrated in a transfer buffer for $10 \mathrm{~min}$. PVDF membrane was activated in methanol for 1 min and then kept in transfer buffer. A sandwich was created by placing the components in the order of base paper stack upon gel, membrane over the gel and paper stack above the membrane. A clean roller was used over each layer to gently even out the setup. The setup was arranged in the cassette and placed in the Bio-rad trans-blot turbo transfer system. The transfer time was set up, and run was completed in $10 \mathrm{~min}$. The transferred membrane was incubated in 5\% skimmed milk at room temperature for $1 \mathrm{~h}$ with constant agitation for blocking. After blocking, the membrane was washed twice with PBS-Tween and finally with PBS. Following the blocking, the membranes were incubated overnight at $4{ }^{\circ} \mathrm{C}$ with primary antibody, which was specific for the target protein with gentle shaking. The next day primary antibody (Caspase 12) solution was replaced, and the membrane was washed twice with PBS-Tween and finally with PBS. The secondary antibody (HRP labelled IgG goat to rabbit antibody) was added and incubated for $4 \mathrm{~h}$. After $4 \mathrm{~h}$, secondary antibody solution was removed and the membrane was washed twice with PBS-Tween and finally with PBS. Now, the membrane was immunodetected by specific substrate such as DAB. The membrane was developed in DAB. The procedure was followed for all other primary antibody (BAX1, Bcl2, cyt c, PARP3, Mcl2). All the primary antibodies and HRP labelled Goat polyclonal to rabbit IgG secondary antibody were procured from Cusabio, USA (Sambrook et al. 1989).

\section{Results}

See Table 1.

- All antibodies were procured from Cusabio, USA

- In vitro anticancer study of nanocompounds-antiproliferative activity

- Cell death induced by apoptosis due to the effect of nanocompounds

- Apoptotic pathway involves several apoptotic genes

- Goat polyclonal to rabbit IgG used as secondary antibody

\section{Protein estimation}

The concentrations of the proteins present in the samples were estimated with reference to the standard BSA as represented in Fig. 1, and the values are tabulated in Table 2. The total protein content in each sample was expressed as mg/g of BSA as represented in Fig. 2 . It could be observed that all the samples exhibited 
Table 1 The six apoptotic proteins under study

\begin{tabular}{llll}
\hline S. no & Primary antibody & Specification & Observed band size \\
\hline 1 & Caspase 12 & Prominent caspase cascade protein & $39,20,30 \mathrm{kDa}$ \\
2 & BAX1 & Prominent caspase cascade protein & $28,12 \mathrm{kDa}$ \\
3 & BCl2 & Apoptosis regulator & $27,19,26 \mathrm{kDa}$ \\
4 & Cyt C & Mitochondrial stress protein & $36 \mathrm{kDa}$ \\
5 & PARP3 & DNA damage protein & $61 \mathrm{kDa}$ \\
6 & Mcl & Regulator of apoptosis & $38 \mathrm{kDa}, 29 \mathrm{kDa}$ \\
\hline
\end{tabular}

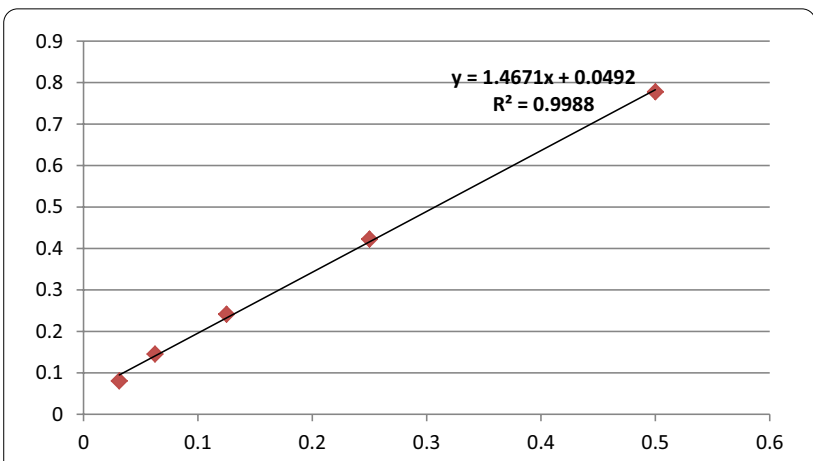

Fig. 1 Standard curve for BSA

Table 2 Quantification of proteins present in the samples

\begin{tabular}{llll}
\hline S. no & Samples & Nanocompounds & $\begin{array}{l}\text { Protein concentration in } \\
\text { the samples } \mathbf{~ m g} \text { /g of BSA }\end{array}$ \\
\hline 1 & S1 & NC4 & 21.36524 \\
2 & S2 & NC5 & 20.7911 \\
3 & S3 & NC6 & 18.72309 \\
4 & S4 & NP12 & 19.53507 \\
5 & S5 & NP6 Dox & 18.19753 \\
6 & S6 & Chit-ND1 & 18.71345 \\
7 & S7 & NP2 & 19.76089 \\
8 & S8 & NC1 & 17.78805 \\
9 & S9 & NC2 & 19.83832 \\
10 & S10 & NP14 & 18.72309 \\
11 & S11 & NC6 Dox & 20.35002 \\
12 & S12 & Chit-ND2 & 19.13784 \\
\hline
\end{tabular}

adequate concentration of proteins with sample 1 with maximum protein content of $21.36524 \mathrm{mg} / \mathrm{g}$ and sample 8 with minimum protein content of $17.78805 \mathrm{mg} / \mathrm{g}$ of BSA.

\section{SDS-PAGE electrophoresis}

$\mathrm{CBB}$ staining was carried out for the preliminary confirmation of various proteins present in the sample as

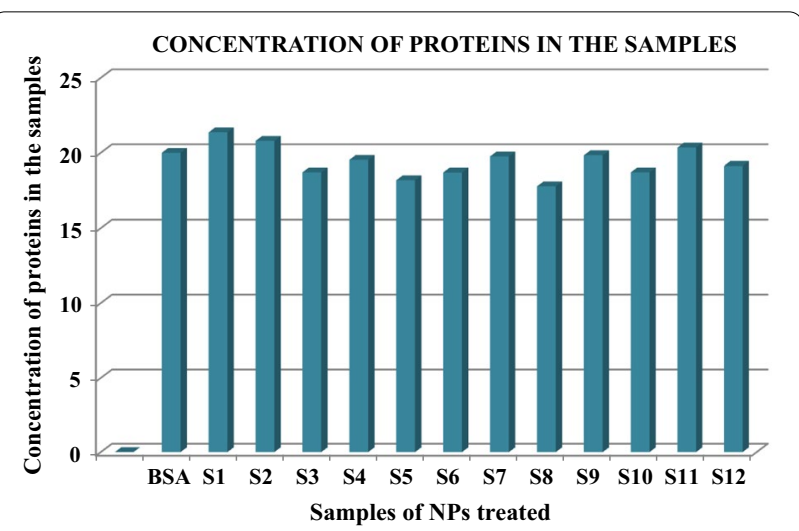

Fig. 2 Concentration of proteins present in the samples

represented in Figs. 3 and 4. The SDS-PAGE gel was stained with Coomassie Brilliant Blue dye to observe the individual protein bands separated based on the molecular weight. The separated bands were visualized which represented the various proteins present in the sample. The six apoptotic proteins of interest were expected for positive bands at $\sim 39 \mathrm{kDa}$ (Caspase 12), $28 \mathrm{kDa}$ (Bax1), $27 \mathrm{kDa}$ (Bcl2), $36 \mathrm{kDa}$ (cyt c), $61 \mathrm{kDa}$ (PARP3) and $38 \mathrm{kDa}$ (Mcl1) kDa as mentioned in Table 1. From the SDS-PAGE gel, it was observed that various protein bands were present near the expected band regions. Further, Western blot was carried out for the detection of apoptotic proteins under study.

\section{Western blot/immunoblotting Expression of apoptotic proteins}

The biosynthesized gold nanoparticles, nanoconjugates, nano-drug conjugates and chitosan-nano-drug conjugates were treated against cervical cancer HeLa cell line. From the inhibitory concentration $\mathrm{IC}_{50}$ values of the anticancer study, it was observed that the nanocompounds have exhibited significant anticancer activities against the treated HeLa cells. The nanocompounds have induced apoptotic pathway in the cell line under study. The apoptotic expression has been studied for 


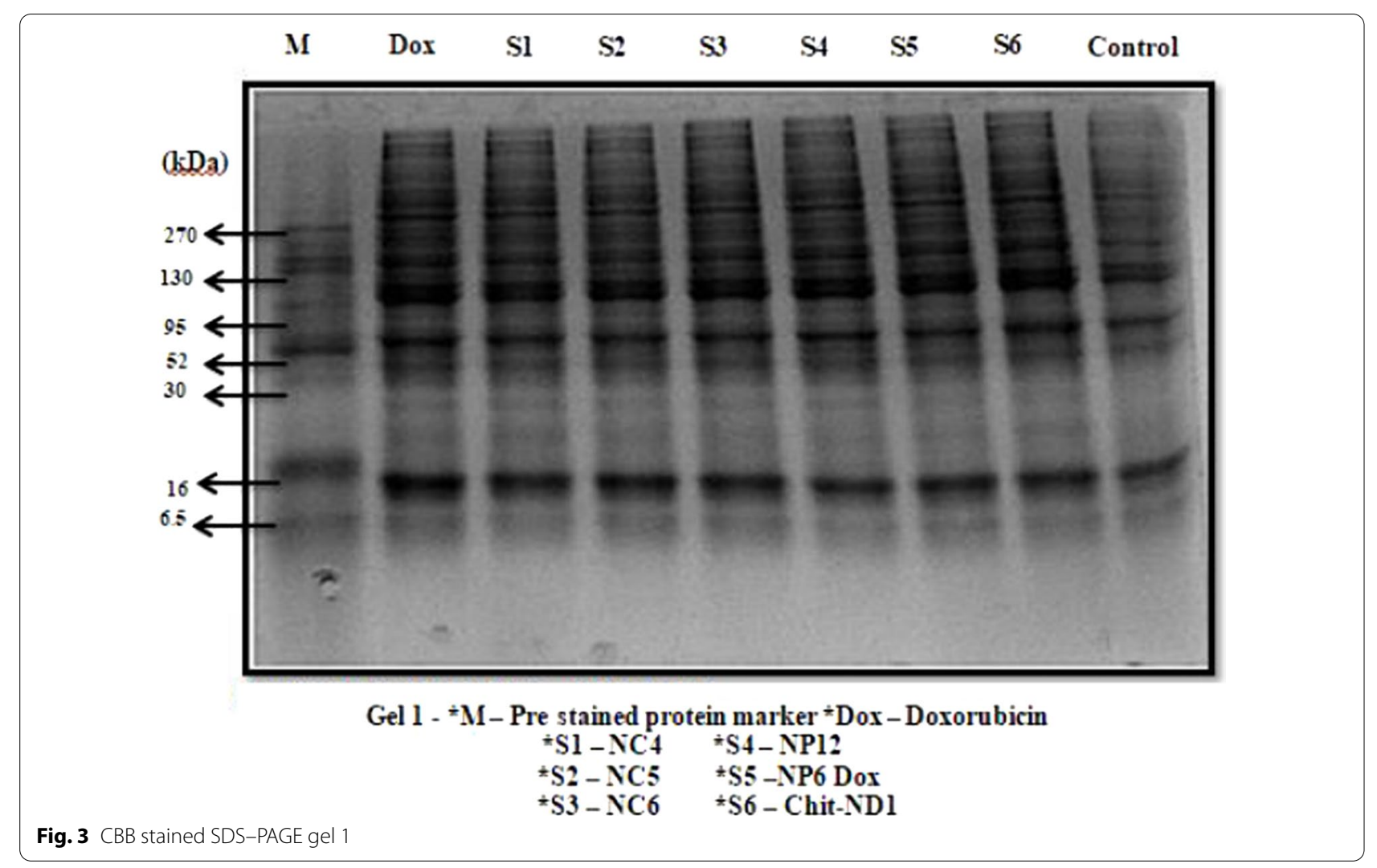

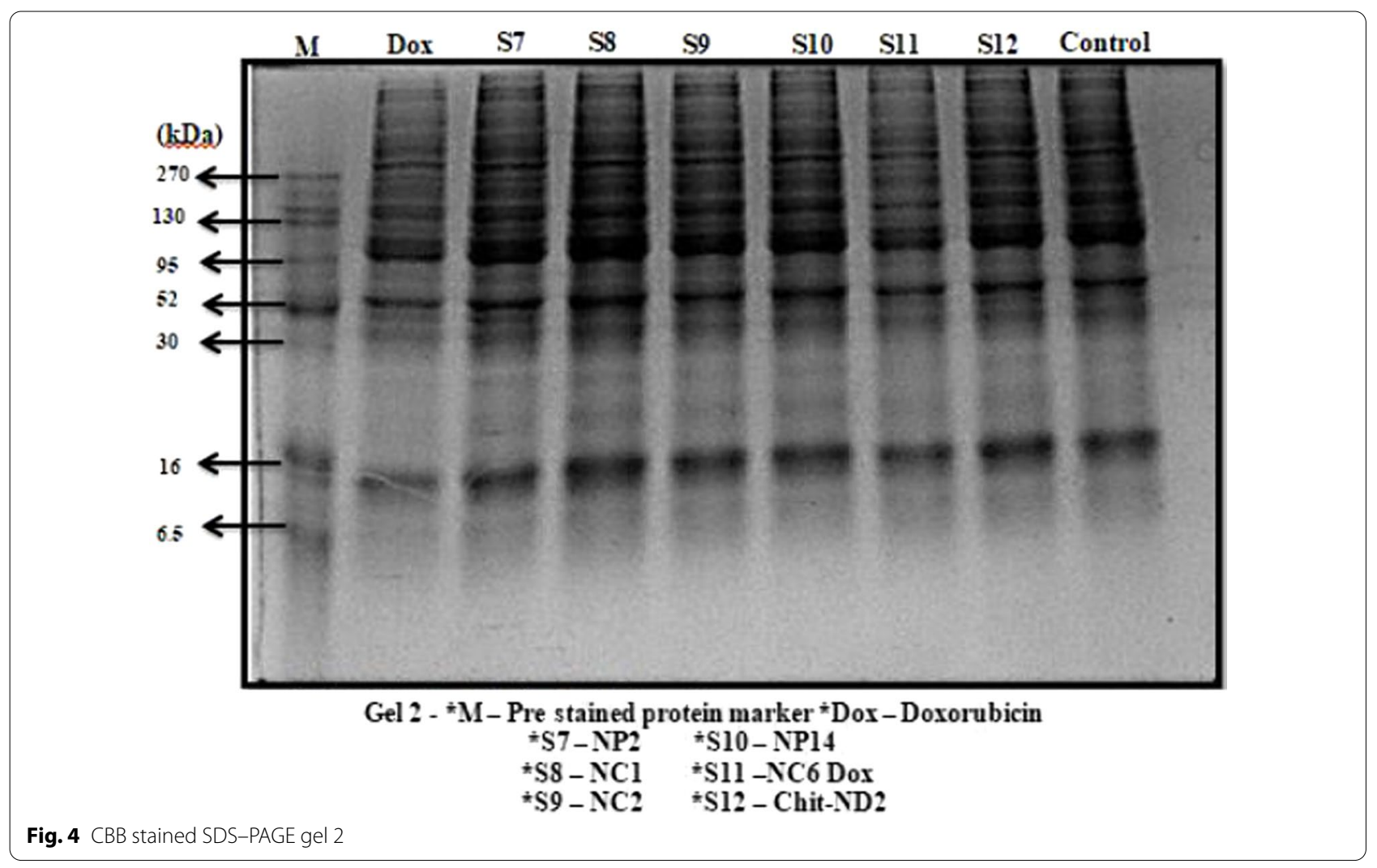



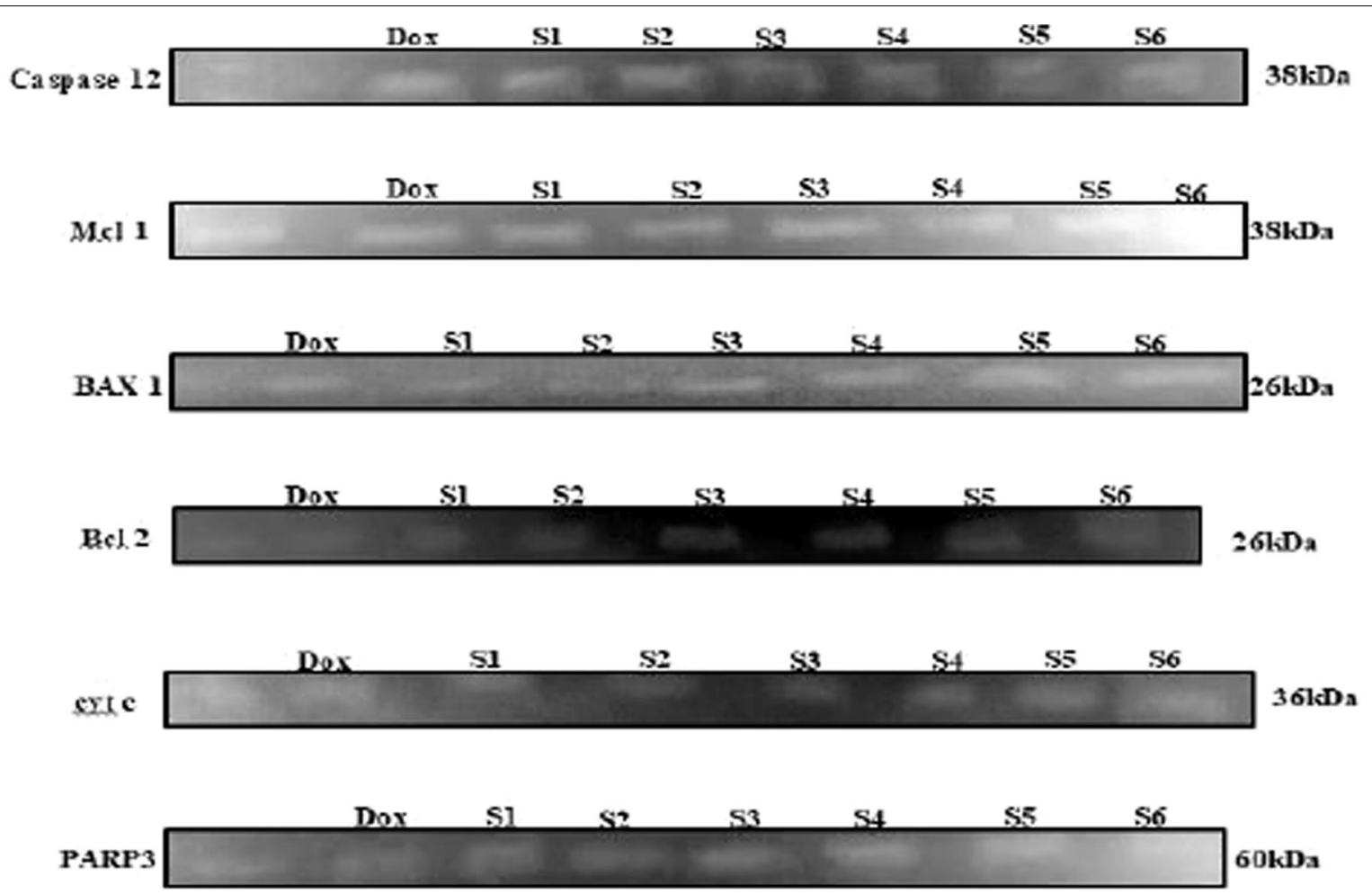

Fig. 5 Gel 1-Expression of apoptotic proteins with respective positive bands at $38 \mathrm{kDa}$ for Caspase 12, $38 \mathrm{kDa}$ for Mcl 1, 26 kDa for BAX, $26 \mathrm{kDa}$ for Bcl 2, 36 kDa for cyt C, 60 kDa for PARP3, Dox—Doxorubicin, S1-NC4, S2-NC5, S3—NC6, S4-NP1, S5—NP6 Dox, S6—Chit-ND1
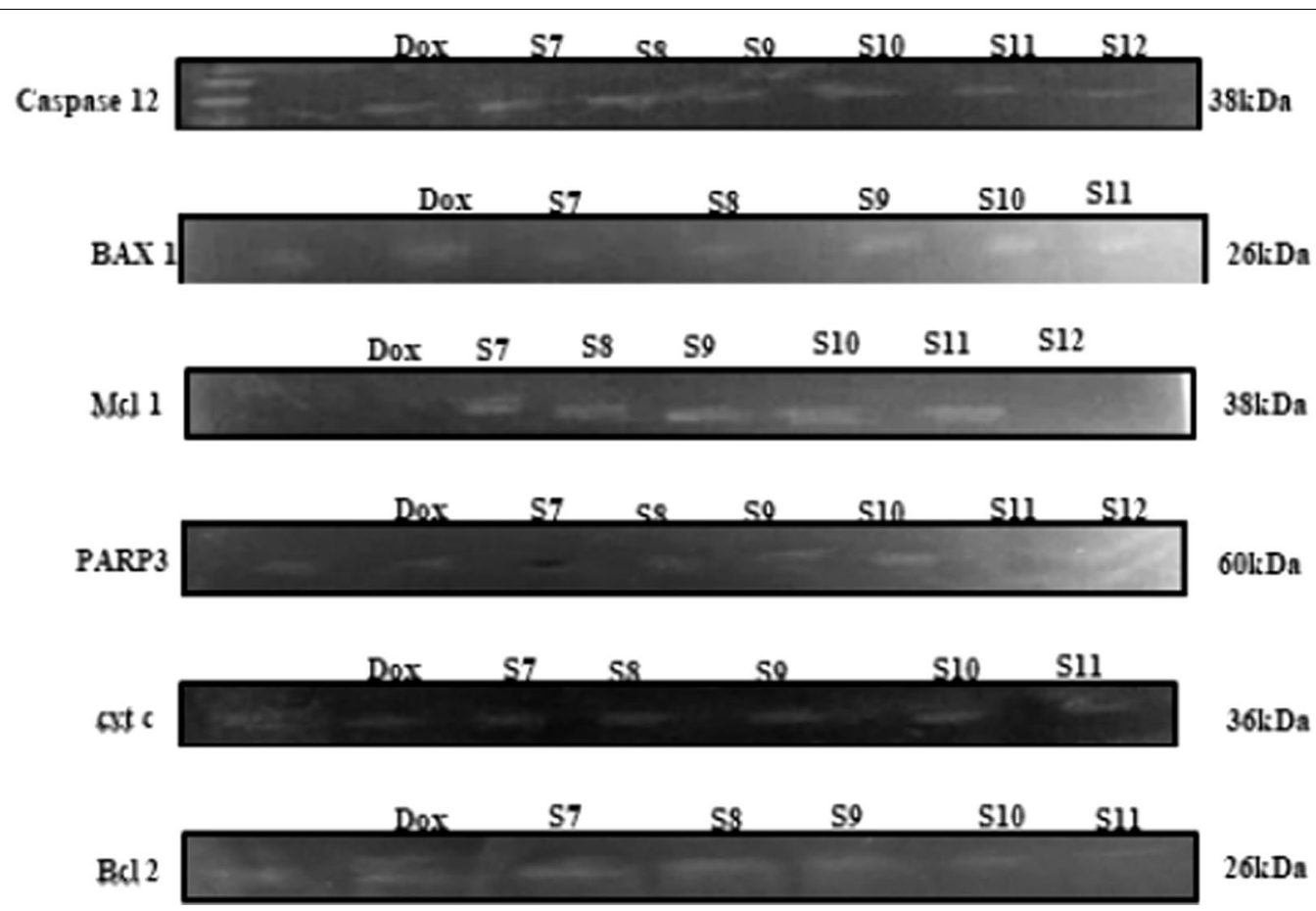

Fig. 6 Gel 1-Expression of apoptotic proteins with respective positive bands at $38 \mathrm{kDa}$ for Caspase 12, $38 \mathrm{kDa}$ for Mcl 1, $26 \mathrm{kDa}$ for BAX, $26 \mathrm{kDa}$ for Bcl 2, 36 kDa for cyt c, 60 kDa for PARP3, Dox—Doxorubicin, S7—NP2, S10—NP14, S8—NC1, S11—NC6 Dox, S9—NC2, S12—Chit-ND2 
six major apoptotic proteins such as Caspase 12, Bcl 2, BAX, Cytochrome c, PARP3 and Mcl 1 as represented in Figs. 5 and 6. From the Western blot, the expression of apoptotic proteins has been observed for Caspase 12 at $38 \mathrm{kDa}, \mathrm{Bcl} 2$ at $26 \mathrm{kDa}, \mathrm{BAX}$ at $26 \mathrm{kDa}$, cyt c at $36 \mathrm{kDa}, \mathrm{Mcl} 1$ at $38 \mathrm{kDa}$ and PARP3 at $60 \mathrm{kDa}$ by NC4, NC6, NP1, NP6 Dox, NC5, NP2, NP2, NC1, NC2, NP14, NC6 Dox, Caspase 12 at $38 \mathrm{kDa}, \mathrm{Bcl} 2$ at $26 \mathrm{kDa}, \mathrm{BAX}$ at $26 \mathrm{kDa}$, cyt $\mathrm{c}$ at $36 \mathrm{kDa}$ and PARP3 at $60 \mathrm{kDa}$ by ChitND1S2, Caspase 12 at $38 \mathrm{kDa}$ and PARP3 at $60 \mathrm{kDa}$ by Chit-ND2, respectively.

\section{Discussion}

$\mathrm{Li}$ et al. (2015) have reported on various events of apoptosis in cervical cancer HeLa cell line. Release of Cytochrome $\mathrm{c}$ by mitochondria marked the cells undergoing apoptosis, with down-regulation of anti-apoptotic $\mathrm{Bcl} 2$, up-regulation of pro-apoptotic BAX and activated expression of Caspase 12. All these events indicated the mechanism of ER stress-specific caspase cascade of apoptosis. The positive band for Cytochrome $\mathrm{c}$ was reported at $26 \mathrm{kDa}, \mathrm{Bcl} 2$ at $26 \mathrm{kDa}, \mathrm{BAX}$ at $21 \mathrm{kDa}$ and Caspase 12 at $38 \mathrm{kDa}$ (Li et al. 2015). In the present study, a similar pattern of apoptotic protein expression was observed with Caspase 12 at $38 \mathrm{kDa}, \mathrm{Bcl} 2$ at $26 \mathrm{kDa}$, $\mathrm{BAX}$ at $26 \mathrm{kDa}$, Cytochrome $\mathrm{c}$ at $36 \mathrm{kDa}$. The apoptotic expression indicated possible ER-mediated caspase cascade of cell death induced by the nanoparticles.

Adhya et al. (2006) have stated on the radiation therapy-induced apoptotic effects on cervical cancer. It was reported that there was an increased apoptotic cell death with up-regulation of pro-apoptotic protein BAX, along with the down-regulation of anti-apoptotic protein Bcl-xL (Adhya et al. 2006). In the present study, the nanomaterials-treated cervical cancer HeLa cell line demonstrated a similar pattern of apoptotic expression like BAX and Bcl2.

Kanipandian et al. (2019) have stated on the events of apoptosis in lung cancer cell line treated with biosynthesized silver nanoparticles. It was reported that the silver nanoparticle initiated an intrinsic apoptotic pathway by activation of mitochondrial-mediated caspase cascade with Caspase 3 and Caspase 9. The cellular events ultimately leading to cell death involve mitochondrial disintegration, DNA damage and nuclear material condensation (Kanipandian et al. 2019). In the present study, the biosynthesized gold nanoparticles using green extracts have been investigated for apoptotic-mediated cell death in cervical cancer cell line. The expression study suggested the apoptotic induction and cell death by activation of Caspase 12 cascade in the nanoparticlestreated HeLa cells.
Szegezdi et al. (2003) have reported on the pivotal role of Caspase 12 in apoptotic cell death. The activation of Caspase 12 led to further regulation of other caspase cascade molecules such as Caspase 9 and Caspase 3 (Szegezdi et al. 2003). In the present study, expression of Caspase 12 was observed in the nanoparticles-treated HeLa cells. The expression of Caspase 12 signified the induced apoptotic cell death in the cancer cells.

Shiraishi et al. (2006) have reported on a detailed study correlating between endoplasmic reticulum, ER stressinduced cell death and mitochondria along with associated cellular events leading to cell death in MEF (mouse embryonic fibroblasts). Cytochrome c was released from mitochondria after initial stress followed by activation of BAX. The cascade of events continued with activation of Caspase 12 along with the response of $\mathrm{Bcl} 2$. The study reported on the active participation of Caspase 12, BAX, Bcl 2 and Cytochrome $\mathrm{c}$ in ER stress-induced apoptotic pathway of cell death (Shiraishi et al. 2006). In the present study, the expression of apoptotic proteins such as Caspase 12, Bcl 2, BAX and Cytochrome c has been observed which are indicative of ER stress-mediated apoptotic pathway of cell death in the HeLa cells treated with gold nanoparticles.

In the present study, the apoptotic expression was checked in the cervical cancer HeLa cell line. The cancer cells were treated by different biosynthesized gold nanoparticles, nanoconjugates, nano-dox conjugate and chitosan-nano-dox conjugate. Further, the nanomaterials were combined with doxorubicin, which was a standard drug used to treat various types of cancer. The combination was formulated in order to enhance the therapeutic index of the drug. Additionally, in order to increase the bioavailability in a sustained release manner, the drug was conjugated with the synthesized nanoparticles and chitosan through STPP-mediated homogenization The expression of apoptotic proteins suggested that the cancer cell death was mediated through ER stress-induced pathway involving the major apoptotic proteins such as Caspase 12, BAX, Bcl2, Cytochrome c, PARP3 and Mcl1. The biosynthesized gold nanoparticles were proven to be effective anti-proliferative agents against cervical cancer.

\section{Conclusions}

The biosynthesized gold nanoparticles, nanoconjugates, nano-dox conjugate, chitosan-nano-dox conjugate were treated against cervical cancer HeLa cell line. The results demonstrated anticancer effects of the nanocompounds implying nanoparticles-induced apoptotic pathway in the cancer cells. Further apoptotic expression was studied for six major apoptotic proteins such as Caspase 12, Bcl 2, BAX, Cytochrome c, PARP3 and Mcl1. All these proteins have crucial role in the regulation of apoptosis through mitochondrial degradation, DNA damage, nuclear 
condensation and eventually cell death of the cancerous cells. It was observed that the apoptotic pathway has been initiated in the cancer cells from the expression of the apoptotic proteins. The expression of apoptotic proteins indicated an ER stress-related apoptotic pathway. The results emphasized that the apoptotic cell death has been induced by the nanomaterials against cervical cancer HeLa cell line. It was observed that the biosynthesized gold nanoparticles exhibited efficient anti-proliferative activity against HeLa cells. The biosynthesized nanoparticles can be further exploited as novel therapeutics in the treatment and management of cancerous conditions.

\section{Abbreviations}

SDS-PAGE: Sodium dodecyl sulphate-polyacrylamide gel electrophoresis; BSA: Bovine serum albumin; PEG: Polyethylene glycol; CBB: Coomassie brilliant blue; HRP: Horseradish peroxidase.

\section{Acknowledgements}

I would like to acknowledge Dr. Sathish Kota, Scientist, TRPVB, TANUVAS, Chennai, and Dr. Harini Challa, Postdoctoral Fellow, TRPVB, TANUVAS, Chennai, for their courteous assistance all through the in vitro studies.

\section{Authors' contributions}

PI designed and directed the study, and KP executed the entire research work from synthesis of NPs, its characterization and preclinical in vivo studies and was the major contributor in writing the manuscript. All authors read and approved the final manuscript.

\section{Funding}

This work was funded by CSIR (Council for Research in Science and Technology) through CSIR-DIRECT SRF funding - (2019-2021) with monthly stipendiary for the researcher, and an Annual Contingency for procuring reagents for research.

\section{Availability of data and materials}

All data and material are available upon request.

\section{Declarations}

Ethics approval and consent to participate

Not applicable.

\section{Consent for publication}

Not applicable.

\section{Competing interests}

No competing interests to declare.

Received: 5 October 2021 Accepted: 22 November 2021

Published online: 07 December 2021

\section{References}

Adhya AK, Srinivasan R, Patel FD (2006) Radiation therapy induced changes in apoptosis and its major regulatory proteins, $\mathrm{BCl}-2, \mathrm{BCl}-\mathrm{XL}$, and $\mathrm{Bax}$, in locally advanced invasive squamous cell carcinoma of the cervix. Int J Gynecol Pathol 25(3):281-287

Eslami A, Lujan J (2010) Western blotting: sample preparation to detection. $J$ vis Exp 44:2359

Gallagher SR (2012) SDS-polyacrylamide gel electrophoresis (SDS-PAGE). Curr Protoc Essent Lab Tech 6:7.3.1-7.3.28

He F (2011) Bradford protein assay. Bio-Protoc 101:e45
Hou Z, Cui Y, Xing H, Mu X (2018) Down-expression of poly(ADP-ribose) polymerase in p53-regulated pancreatic cancer cells. Oncol Lett 15(2):1943-1948

http://atlasgeneticsoncology.org/Genes/GC_BCL2L1.html. Accessed 12 Sept 2019

https://www.protocolsonline.com/protein-science/coomassie/. Accessed 6 Jan 2019

Kalai M, Lamkanfi M, Denecker G, Boogmans M, Lippens S, Meeus A, Declercq W, Vandenabeele P (2003) Regulation of the expression and processing of caspase-12. J Cell Biol 162(3):457-467

Kamala Priya MR, Iyer PR (2014a) Extracellular rapid biosynthesis of AuNPs using various green extracts of plants. Int J Mol Biol Biochem 2:33-40

Kamala Priya MR, Iyer PR (2014b) Studies on the various parameters underlying the Synthesis of nanoparticles and the in-vitro stability of nanoparticles. Front Biotechnol 1:1-4

Kamala Priya MR, lyer PR (2014c) Anticancer studies of the synthesized AuNPs against MCF 7 breast cancer cell line. Appl Nanosci 5:443-448

Kamala Priya MR, Iyer PR (2015a) Comparative study on the characterization of AuNPs synthesized using various plant extracts. Int J Phytother 5:17-21

Kamala Priya MR, Iyer PR (2015b) Applications of the green synthesized AuNPs-antimicrobial activity, water purification system and drug delivery system. Symbiosis 2:1-4

Kamala Priya MR, Iyer PR (2019a) Anti-cancer study in HeLa cell line of phytosynthesized gold nanocompounds using Andrographis paniculata (nilavembu): characterization, optimization, phytochemical analysis \& antimicrobial study. Indian J Appl Res 9:24-27

Kamala Priya MR, lyer PR (2019b) Apoptotic activity in cervical cancer HeLa cell lines treated with chitosan nanoconjugated drug doxorubicin: as nanocarrier for drug delivery. Proc Mater 1:42-53

Kamala Priya MR, lyer PR (2020a) Anti-proliferative effects on tumour cells of the synthesized gold nanoparticles against Hep2 liver cancer cell line. Egypt Liver J 10:1-12

Kamala Priya MR, lyer PR (2020b) Antineoplastic activity of synthesized gold nanoparticles and gold nanoconjugate against Hela cervical cancer cell line. Indian J Appl Res 10(12):1-4

Kamala Priya MR, lyer PR (2020c) A comparative anticancer study of biosynthesized nanoparticles, doxorubicin \& nano-dox conjugate against cervical cancer HeLa cell line. Int J Sci Res 9(12):1-4

Kamala Priya MR, Iyer PR (2020d) Acute \& chronic toxicological studies of the biosynthesized gold nanoparticles on Wistar rats (accepted)

Kamala Priya MR, lyer PR (2021) Characterization of the biosynthesized gold nanomaterials: spectroscopical, dimensional, morphological, stability \& structural analysis. IJBNN 4:235-263

Kanipandian N, Li D, Kannan S (2019) Induction of intrinsic apoptotic signaling pathway in A549 lung cancer cells using Silver nanoparticles from Gossypium hirsutum and evaluation of in vivo toxicity. Biotechnol Rep 23:e00339

Li D, Li L, Li P, Li Y, Chen X (2015) Apoptosis of HeLa cells induced by a new targeting photosensitizer-based PDT via a mitochondrial pathway and ER stress. Onco Targets Ther 8:703-711

Ludwig AK, De Miroschedji K, Doeppner TR et al (2018) Precipitation with polyethylene glycol followed by washing and pelleting by ultracentrifugation enriches extracellular vesicles from tissue culture supernatants in small and large scales. J Extracell Vesicles 7(1):1528109

Ma DD, Yang WX (2016) Engineered nanoparticles induce cell apoptosis: potential for cancer therapy. Oncotarget 7(26):40882-40903

Priya MRK, Ashokkumar M, Precilla LK et al (2021) Nanomedicine perspective in HIV therapy: biosynthesized gold nanoparticles exhibiting enhanced anti-HIV property. Beni-Suef Univ J Appl Sci 10(23):1-12

Sambrook J, Fritsch ER, Maniatis T (1989) Molecular cloning: a laboratory manual, vol 3, 2nd edn. Cold Spring Harbor Laboratory Press, Cold Spring Harbor

Shiraishi H, Okamoto H, Yoshimura A, Yoshida H (2006) ER stress-induced apoptosis and caspase-12 activation occurs downstream of mitochondrial apoptosis involving Apaf-1. J Cell Sci 119:3958-3966

Szegezdi E, Fitzgerald U, Samali A (2003) Caspase-12 and ER-stress-mediated apoptosis: the story so far. Ann N Y Acad Sci 1010:186-194

\section{Publisher's Note}

Springer Nature remains neutral with regard to jurisdictional claims in published maps and institutional affiliations. 